\title{
Bone Metastases Prevention
}

National Cancer Institute

\section{Source}

National Cancer Institute. Bone Metastases Prevention. NCI Thesaurus. Code C15529.

Methods used to prevent the spread of cancer from a primary tumor site to the bone. 